\title{
EL REVERSO DEL BIENESTAR. LA CREACIÓN DEL DEPARTAMENTO \\ DE BIENESTAR SOCIAL Y EL REFORZAMIENTO DEL CONTROL SOCIAL \\ en el Norte Grande a Principios de los años veinte
}

\author{
Pablo Artaza Barrios ${ }^{1}$
}

\begin{abstract}
Resumen
Este artículo analiza la creación del departamento de Bienestar Social de la Asociación de Productores de Salitre de Chile, en el contexto de la crisis económica de principios de la década de 1920. Dicha institución fue una de las primeras iniciativas donde se conjugaron los intereses estatales y empresariales hacia una necesidad central de la industria salitrera: la modernización de las relaciones industriales, que involucraban tanto el desafío de realizar una intervención estatal en materia social, como la modernización productiva de este sector industrial. Por lo tanto, proponemos que en la fundación del departamento de Bienestar Social confluían, conflictivamente, los nuevos esfuerzos orientados a mejorar la condición de los trabajadores salitreros y los viejos mecanismos de control social sobre la mano de obra, profundizando en torno a uno de los mecanismos empleados para lograr esto último.

Palabras claves: crisis salitrera - relaciones industriales - paternalismo -
\end{abstract} control social. This article analyzes the creation of the Social Welfare Department at the Chilean Nitrate Producers Association, in the context of the economic crisis of the early Twenties. The mentioned Department was one of the first initiatives where both the State and the Entrepreneurs worked together toward a common necessity: the modernization of the industrial relationships, which involved both the challenge of making a state intervention in social matters as well as the productive modernization of this particular industrial sector. Therefore, we propose that at the very foundation of the Social Welfare Department we could perceive a conflictive situation between new efforts oriented to improve the situation of the nitrate workers, depening around the mechanisms to achieve this last.

Key words: nitrate crisis - industrial relationships - paternalism social control.

Recibido: octubre 2015. Aceptado: enero 2016.

\section{* La década del 20 se abre ante un escenario DE CRISIS}

Si bien la industria salitrera tenía entre sus aspectos distintivos la inestabilidad — llegando a conformarse, como ha destacado Sergio González, una identidad popular caracterizada por la crisis (1991: 53) —, ya sea que esta fuera introducida artificialmente para mantener altos precios en el mercado mundial o porque correspondiera a las típicas fluctuaciones comerciales de un producto orientado a satisfacer una demanda que no controlaba, lo cierto es que, desde la post Primera Guerra Mundial, se acrecienta la profundidad de las fluctuaciones e inestabilidad, sumándose ahora el rol explicativo que en ellas jugaba un nuevo factor, el que cada vez iría cobrando mayor importancia, como lo fue la disputa de mercado por parte de la progresiva competencia jugada por el abono artificial. Debido a esto, la década de los veinte está cruzada por la radicalización definitiva de la crisis (Pinto 1996; González 2015), con su conocida secuela de paralización de faenas, migraciones y desplazamientos de pampinos cesantes y albergados (Pinto 1999; Recabarren 2003: 2327).

Como indicábamos, el período considerado en este artículo corresponde a una etapa especialmente compleja tanto para el escenario salitrero como para el conjunto del país, el cual se debate entre las recurrentes crisis económicas y la crisis política, que le llevarán al término de una etapa dentro de la periodificación tradicional de la historia de Chile. Por ello, debe insertarse comprensivamente dentro de la etapa final la cuestión social y su de

1 Departamento de Ciencias Históricas, Universidad de Chile. Av. Capitán Ignacio Carrera Pinto 1025, Nuñoa, Santiago, CHILE. Email: partaza@u.uchile.cl 
safío en torno a las necesidades de transformación social, ya que tanto a nivel nacional (Morris 1967) como local, había venido gestándose la articulación de una necesidad social, que una vez articulada como protesta popular, demandaba un complejo programa de intervención, ya fuese en un registro eminentemente armonizador (Sánchez 2013), o a través de la dictación de un completo programa de legislación social orientado a satisfacer la demanda social (Pinto 1997; Artaza 2006). Así enmarcado, hacia los años veinte y acicateado por los desafíos planteados ante la necesidad de adecuarse a un enrarecido contexto de crisis económica y política, tanto el país, como por extensión, una de las industrias que sirvió de puntal a ese Chile que se precipitaba al abismo, debieron replantearse profundamente los principios económicos, políticos y sociales sobre los que se habían construido, generando alternativas para enfrentar estos grandes desafíos, algunas de las cuales fueron nuevas - como la modernización industrial - y otras no tanto, como el refuerzo del control social, de las que en esta oportunidad profundizaremos en torno a las circunstancias que rodearon a su etapa temprana de instalación, por medio de la creación del departamento de Bienestar Social de la Asociación de Productores de Salitre de Chile.

Ya al despuntar el año 1919, la crisis salitrera se anunciaba en toda su extensión y profundidad, haciendo imposible separar el caso que analizaremos - el surgimiento del departamento de Bienestar Social - de la crisis por la que atravesaba la industria del nitrato. A tal punto que, que de acuerdo a informaciones entregadas por el periódico La Provincia de Iquique, en su edición del 11 de enero de 1919, tan solo durante el último mes del año 1918, se consignó la paralización de 19 salitreras, correspondientes a las oficinas Abra, Ángela, Barcelona, Camiña, Catalina, Cóndor, Josefina, Lagunas, Nor Lagunas, Paccha, Progreso, Puntunchara, Recuerdo, Sacramento, Santa Rita, Santiago, Sur Lagunas, Tránsito y Valparaíso; generando con ello la cesantía de casi cuatro mil trabajadores directos, sin contar a sus familiares. A medida que avanzaba el año, tanto en Tarapacá como en Antofagasta se produjo una fuerte disminución en la capacidad exportadora de esta industria, la que durante el mes de mayo llegó a caer en un muy considerable 90\% respecto del volumen observado al mes de noviembre del año anterior. Para el año siguiente, pese a registrarse una pequeña alza en la producción salitrera, la crisis ya estaba instalada, tanto así, que 1921 marca el inicio de una nueva y especialmente cruenta crisis salitrera, originada por la incapacidad de este sector minero de poder enfrentar exitosamente "las nuevas características del mercado internacional”. Según Alejandro Soto, esta crisis se habría precipitado como manifestación tardía de las profundas alteraciones financieras propias del período del armisticio, lo que acarrearía una disminución considerable - a un tercio, indicaría este autor- del poder mundial de compra del salitre, lo cual se reforzaría por la fijación de un alto valor a su venta (Soto 1998: 181).

Ya el último trimestre del año anterior, correspondiente a 1920, habría cerrado con una paralización de la comercialización del nitrato, repercutiendo en una rápida acumulación del producto tanto en las costas chilenas como en Estados Unidos y Europa, generando una paralización de las actividades extractivas de mayor profundidad aún que la registrada en 1919, y que se extendería durante todo ese año y hasta inicios de 1923 (Couyoumdjian 1986; Pinto 1996, 1999; Pinto y Valdivia 2001: 70-88; Vial 2001: 220-228). La crisis salitrera, traducida en la paralización de la mayoría de las oficinas que elaboraban el mineral, azotaba con especial dureza a los sectores populares de las nortinas provincias de Tarapacá y Antofagasta, quienes veían día a día aumentar el número de desocupados. Para los directamente involucrados, tal como reseñaba uno de sus periódicos, el conocido El Despertar de los Trabajadores, en su edición del 7 de enero de 1921, "la crisis porque atraviesa la región salitrera, marcará para el pueblo de Tarapacá, una nueva era de hambre. (...) Todos los días vemos que deja de elaborar una oficina, y el pobre roto, el infeliz pampino, emprende su marcha hacia sus lares, de donde lo trajeron, por medio de mentiras inicuas", dejando en claro con ello que, para los pampinos, ante la falta de trabajo solo quedaba la alternativa de retornar, como dejaría establecido esta misma publicación dos días después, en su nota dramáticamente titulada "La elocuencia del hambre". De hecho, según la información de la Oficina del Trabajo, tan solo durante ese año, de un total de obreros cesantes de las provincias salitreras de Tarapacá y Antofagasta que alcanzó a los cuarenta y cinco $\mathrm{mil}^{2}$, aproximadamente 40.000 debieron ser

2 Archivo Nacional de la Administración (ARNAD), Fondo Oficina del Trabajo, Tomo 77, año 1921. Comunicación enviada al Director de la Oficina Internacional del Trabajo en Ginebra, 14 de noviembre de 1921. 
trasladados hacia el centro del país ${ }^{3}$. Lo que reactivó la que sería la respuesta estatal frente al desafío que esto significaba, desplegando esfuerzos para facilitar tanto el traslado de los trabajadores desocupados, su alojamiento más o menos provisorio - por medio de una sistema de albergues fiscales-y la instalación de un servicio de Colocaciones, encargado de atender a la relocalización laboral de los desocupados.

Por su dramática secuela, la etapa inicial del año 1921 resultó especialmente crítica, ya que la generalizada paralización de las actividades extractivas por parte de la industria salitrera redundó en una agudización de la crisis del trabajo, la que, a diferencia de los años anteriores, esta vez activó una fuerte respuesta popular. Así, tal como lo ha reseñado Floreal Recabarren - quien es el que más detenidamente ha examinado la matanza de San Gregorio - ante la indefensión en que quedaban los obreros y sus familias producto de la cesantía, la Federación Obrera de Chile desde el año anterior venía encabezando una campaña destinada a obtener el correspondiente desahucio en el caso de que una oficina apagara sus fuegos. Acción "federada" que cobró fuerzas a medida que se extendía la paralización, especialmente en Antofagasta, donde, ante el anuncio del término de las labores por parte de ocho oficinas del cantón Aguas Blancas, en una de ellas se decidió resistir el desalojo hasta obtener de la empresa la correspondiente compensación. Para este autor, "El rumor de la crisis había alterado los espíritus. Pero cuando el rumor se hizo realidad y poco a poco la comunidad salitrera fue sintiendo cada vez más cercana la crudeza de la cesantía, la angustia se transformó en rebeldía" (Recabarren 2003: 55).

De acuerdo a diversos relatos, el 3 de febrero, mediante trenes debidamente dispuestos para ello, los obreros de la salitrera San Gregorio debían abandonar sin desahucio alguno la oficina, ya que habían sido previamente notificados por la administración. Noticia ante la cual los trabajadores — bajo la conducción de la FOCH localhabían anunciado su decisión de permanecer y mantener la oficina en operaciones (Zig-Zag, 12 de febrero de 1921), por lo que, en previsión de esta resistencia, la faena se

3 ARNAD, Fondo Oficina del Trabajo, Tomo 69, año 1921. Memorando enviado al Ministro de Industrias y Obras Públicas, 21 de agosto de 1921. había reforzado con presencia militar. Pese a ello, hacia las cinco de la tarde, los trabajadores de la oficina marcharon hacia la casa de Administración para plantear sus demandas, formando una concurrida columna, ya que el contingente obrero se había reforzado con trabajadores de las oficinas vecinas. Con este marco de presión, los dirigentes de los trabajadores habrían buscado entablar una negociación que encontró el peor de los desenlaces posibles, ya que derivó en un enfrentamiento entre la columna obrera y los militares que resguardaban la oficina, el que dejó un triste saldo de muertos que alcanzó a 65 trabajadores, el administrador de la salitrera y tres soldados del regimiento Esmeralda, entre los que contaba el oficial a cargo del resguardo de la oficina (Vitale 1993; Recabarren 2003). Desenlace que, lejos de contribuir a disminuir la tensión social en las tierras salitreras, aumentó su crispación, la que se manifestó en amenazas de una huelga general y que llevó al ministro Pedro Aguirre Cerda a inspeccionar directamente la zona entre los últimos días del mes de marzo y los primeros de abril, gracias a lo cual pudo formarse una mejor impresión de la realidad que afectaba a los trabajadores del área y, como veremos, colaborar directamente en la introducción de mejoras (Recabarren 2003: 33-40).

\section{* La CRisis, las amenazas de intervención y LA TRANSFORMACIÓN DE LA INDUSTRIA}

La profundidad de estas recurrentes crisis salitreras $y$, sobre todo, la inestabilidad reinante en sus precios post Primera Guerra Mundial, jugaban un peligroso papel irradiador hacia el conjunto de la economía nacional, el que se explicaba principalmente por el alto nivel de participación que esta industria poseía en el conjunto de las finanzas públicas. Ello había generado un debate nacional que, en lo general, tendía crecientemente a cuestionar la gran "liberalidad" con que se había conducido esta industria. Si para 1880, una comisión gubernativa indicaba que "...es de desear que Chile acate y mantenga la primera de las reglas de la buena economía pública, que condena toda intervención gubernativa en los dominios especiales de la industria" (Comisión Consultiva 1880: 15), hacia mediados de la segunda década del siglo XX esta tendencia estaba en revisión, y ya para 1916 una comisión de la Cámara de Diputados presentaba un proyecto en torno a la necesidad de estudiar la reorganización de la industria salitrera por medio de una "Colectividad 
Salitrera", institución que, con participación estatal, estipulara una concentración de las ventas en términos muy semejantes a los que, años más tarde, terminaría siendo la Compañía de Salitres de Chile (COSACH) y la Corporación de Ventas de Salitre y Yodo de Chile (COVENSA) (Couyoumdjian 1986: 120). Esto, en términos generales de la industria, coincidía con lo que una nueva Comisión Consultiva, esta vez de 1916, indicó en cuanto a la necesidad de intervención estatal respecto de la situación de los trabajadores. Presidida por el ministro de Hacienda, Enrique Oyarzún, y compuesta por los parlamentarios Juan Enrique Concha y Julio Philippi, esta delegación fue enfática al señalar:

"La experiencia uniforme del siglo XIX ha demostrado que las clases trabajadoras no pueden quedar jamás abandonadas a las contingencias de la vida industrial, y que necesitan el amparo de la ley. De ahí ha nacido la legislación social. Esta experiencia ha consagrado el derecho del Estado a intervenir en las relaciones entre patrones y obreros, relaciones que ha reglamentado cuidadosamente, para evitar en especial los abusos a que los obreros están expuestos como consecuencia inevitable de su inferioridad económica" (Oyarzún, Concha y Philippi 1917: 19).

Este último factor, a la luz de los acontecimientos ocurridos en la oficina salitrera San Gregorio, se volvía más urgente de encarar.

Frente a este doble desafío de intervención sobre la industria salitrera -uno directamente económico y otro más abiertamente social-, y obviamente acicateados por su propio declive empresarial frente a la competencia del salitre artificial, los propios salitreros deciden emprender su transformación, la que pasaba por someterse voluntariamente a un proceso de modernización. Un primer paso, en esta línea, lo constituyó la transformación de su propia entidad de representación patronal, y ante el incremento de la presión gubernativa en torno a la intervención del sector, la tradicional Asociación Salitrera de Propaganda -institución que desde 1894 había desempeñado un rol central en la coordinación de los productores salitreros y en una importante dimensión corporativa salitrera - se disolvió, y a inicios de 1919 convocó a la creación de la nueva Asociación de Productores de Salitre de Chile, la que estaría dirigida por catorce integrantes elegidos en representación de los productores y dos representantes del gobierno, siendo una instancia que re- cogía parte importante de los elementos sugeridos por la comisión parlamentaria que atendía a la reorganización del sector (Couyoumdjian 1986: 188ss.). Así, entre sus funciones destacaban:

- Llevar a cabo la propaganda comercial y científica del salitre.

- Recopilar estadísticas relacionadas con la industria.

- Fomentar nuevos métodos de producción que permitan un uso más económico de las materias primas y reduzcan los costos.

- Estimular las invenciones y los métodos que extiendan los usos del nitrato de soda.

- Fijar la cantidad de salitre que deba ser exportada anualmente.

- Establecer y modificar periódicamente el precio del salitre, y vender la producción por cuenta de sus asociados.

- Establecer agencias en el extranjero y crear depósitos para regularizar su provisión y consumo.

- Estudiar medios para mejorar el abastecimiento de agua en las oficinas, el ensacado y transporte de salitre a la costa y los métodos de embarque.

Como se puede apreciar, parte importante de sus áreas prioritarias estaban orientadas a una modernización de los procesos productivos, lo que reflejaba una de las áreas que requería más cambios en la reorganización de la industria. Ya desde fines de la década de 1910, la forma de generar el producto del salitre había comenzado a experimentar diversas pequeñas mejoras: desde la introducción temprana de palas mecánicas a vapor para extraer caliche, a la introducción de dragas excavadoras, el reemplazo de picotas por perforadoras neumáticas, la introducción de camiones para el acarreo del caliche, el reemplazo del carbón por petróleo, etc. La dinámica se profundizó con esta institución, tal como destacara Gonzalo Vial, para quien,

“(...) Tras la Gran Guerra, y más acentuadamente con la crisis del 21, la Asociación se interesó por el avance técnico. Para difundirlo, creó la revista Caliche el año 1919; que completaría una década de publicación. Además recabó los servicios de un químico y profesor universitario, el norteamericano F.G. Donnan [...quien] vino a Chile y estudió el funcionamiento de 26 oficinas (19181919). De esos informes surgió el Departamento de Investigación Cientifica de la Asociación (1921)" (Vial 2001: 225). 
Estas modificaciones, en su conjunto, actuaron como antesala o contribuyeron directamente a la adopción de la gran modernización productiva de principios de la década siguiente: la introducción del método Guggenheim, el que destacaría por su eficiencia, al ampliar la mecanización de las faenas extractivas en unión con la posibilidad de tratar minerales de baja ley, junto a un menor consumo energético en el proceso de lixiviación (González 2003); transformación que resultó fundamental, en cuanto permitió comenzar a superar la relación, tradicionalmente construida en esta industria, entre una amplia disponibilidad - y bajo costo - de la mano de obra, y el desincentivo que generaba en las necesidades de renovación tecnológica (O’Brien 1989: 136).

Por esta misma relación señalada es que, dentro de las transformaciones que implicaba la modernización de la industria salitrera, la de índole productiva consistía en solo una de las grandes piezas susceptibles de renovación, ya que la adopción de los principios de la moderna organización industrial implicaba, también, una serie de trasformaciones en relación a la fuerza de trabajo. O en las palabras que lo explicaba un observador de época, quien se encontraba directamente involucrado:

"Cuando las industrias, cualquiera que ellas fueren, son tan pequeñas que un hombre puede atender totalmente a su dirección, se tiene el más simple organismo industrial. Pero éstas se desarrollan y crecen. Las exigencias del competidor hacen necesaria una mayor eficiencia industrial y un estudio más detenido de los procedimientos para alcanzarla. Nacen nuevos organismos, nuevos engranajes del mecanismo comercio-industrial. Pero a la par que el estudio detenido de la maquinaria y un cuidado minucioso de su funcionamiento traen como consecuencia lógica un mayor rendimiento, la máquina humana, el factor hombre, también reclama la misma cuidadosa atención, haciendo evidente la necesidad de dedicar estudio y atención" (Torreblanca 1928: 37).

Bajo el planteamiento anterior, el autor se refería - aunque eufemísticamente - a aquellas transformaciones relativas a las relaciones laborales y que han sido analizadas por Richard Sennet, quien les aplica el concepto de "paternalismo", que sería adecuado para caracterizar las relaciones sociales de trabajo, las cuales, bajo este propósito modernizador, se desarrollaron en el contexto de la industria en Estados Unidos y Francia. Según este autor, ante el proceso consustancial de pérdida de los lazos fami- liares tradicionales implícito en las modernas formaciones capitalistas, desde las cúpulas administrativas surgió la idea de reproducir mecanismos que intentaran recuperar los valores atribuidos al núcleo familiar y su efecto modelador de las conductas. De este modo, habría surgido la metáfora del paternalismo como una herramienta para asociar simbólicamente la figura perdida del padre con la del patrón y/o la empresa misma, ya que "en la medida en que funcionara esa invocación, se esperaba que los sometidos fueran leales, agradecidos y pasivos" (Sennet 1982: 61), destacando con ello ideas como las de las comunidades industriales saintsimonianas, en donde la familia era un apéndice de la fábrica y, por otro lado, las de Waltham y Lowell, en donde el control sobre los trabajadores excedía el lugar de trabajo, permitiendo ejemplificar claramente la forma en que, bajo este principio, comenzó a concebirse la moderna organización industrial en su relación con la mano de obra. Al ceñirse por este modelo, los industriales, "al hacerlo aspiraban a la cohesión comunal y a extraer de esta comunidad estable de trabajadores unas tasas más altas de productividad" (Sennet 1982: 65). Éste era precisamente el desafío que rápidamente debían encarar los salitreros, ya que este nuevo frente de transformación de la industria presentaba la doble ventaja de ofrecer una estrategia orientada a un control racional de la producción, así como de reforzar una de sus formas tradicionales de enfrentar el conflicto entre capital y trabajo.

\section{* La Asociación de Productores de Salitre de Chile, la comisión y el departamento de Bienestar Social}

Como ya señalábamos, al calor del aumento de la tensión social suscitada por la crisis salitrera y su capacidad de irradiación sobre el conjunto de la sociedad (Pinto 2013; Grez 2011), otro frente de trasformaciones de este sector industrial lo constituían las exigencias que desde algunos años antes venían instalándose en sectores cada vez más amplios de la clase política, y que se orientaban hacia la necesidad de intervenir en torno a las relaciones laborales (Morris 1967; Yáñez 1999; Grez 2001). Así quedaba demostrado en diversos indicadores posibles, para lo que bastaría reiterar lo planteado por el informe de la Comisión Consultiva del año 1916, y reforzado posteriormente por la del año 1919, ante lo cual la intervención social en Chile se hacía inevitable; esto, finalmente, llevó a que el Estado impulsara políticas de bienestar social especial 
mente aplicables a la minería, en general, y a la industria salitrera, en específico (Aguilera 2015: 222-228). Al respecto, según destaca Juan Carlos Yáñez,

\section{“(...) bajo la influencia de la corriente socio-liberal, comenzó a} destacar el rol del trabajo como un factor de la producción y de la estabilidad social. Esta corriente alcanza su máxima expresión con la campaña presidencial de 1920, tanto en los candidatos Arturo Alessandri, como Luis Barros Borgoño. Para ambos la solución al conflicto social pasaba por reconocer el aporte del factor trabajo en la organización social y el progreso económico, promoviendo mejores condiciones en la clase proletaria" (Yáñez 2008: 224).

A este esfuerzo común de carácter reformador se sumaba el propio diagnóstico de los salitreros, en su necesidad de dedicar "estudio y atención" a esta otra esfera necesitada de modernización del sector industrial, especialmente sensible en un rubro como el salitrero, tan altamente dependiente de las necesidades de mano de obra y donde este componente alcanzaba un porcentaje importante de su estructura de costos. Así, cediendo frente a las presiones de trasformación desde el sistema político, ejercidas esta vez por Pedro Aguirre Cerda -el joven ministro del interior de Alessandri-, la nueva institucionalidad patronal aceptó implementar para la industria una comisión de Bienestar Social, introduciendo una novel institucionalidad empresarial que tuvo una amplia irradiación territorial y una larga pervivencia en el país.

Resulta importante precisar que las comisiones de Bienestar Social, impulsadas por varias industrias capitalistas de la época, fueron parte de lo que se ha entendido como formas de control "extensivas". Pues, éstas se habrían caracterizado por rebasar el lugar de trabajo, es decir, por constituir "una intervención sobre los ámbitos sociales de recreación, el ocio y de la vida privada de los trabajadores, pero también de sus familias, que incluye crearlas en caso de que no las haya" (Venegas 2014: 3). Según Oscar Peñafiel, quien sigue los planteamientos teóricos de J. P. de Gaudemar (1991), este tipo de prácticas se habrían aplicado en función de conseguir en los trabajadores la "moralización y encuadramiento en un tipo de relaciones sociales, acorde al universo cultural de las élites industriales y las necesidades de la acumulación capitalista" (2014: 62). Por esto, las formas de control extensivo, impulsadas desde las empresas en esta época, tendieron a mantener una estrecha relación con las políticas de bienestar social llevadas a cabo desde el Estado. De tal modo lo señala Hernán Venegas para el caso de las políticas de bienestar, impulsadas unos pocos años más tarde — durante la década de 1930 - en la minería del carbón en Lota, donde los departamentos de Bienestar habrían profundizado y perfeccionado las "prácticas de paternalismo industrial en su vertiente burocratizada y las pusieron en consonancia con la legislación social promovida por el Estado, generando una notable simbiosis entre la propuesta benefactora de las empresas y el asistencialismo estatal" (Venegas 2015: 242).

Esta asociación estatal privada, según el autor, habría tenido un efecto paliativo para la miseria en que vivían sumidos los trabajadores, así como para contener, en alguna medida y por algunos años, el radicalismo obrero. Esta fusión de intereses, que resulta en una forma de coordinación de trabajo entre las empresas y el Estado, corresponde a una modalidad particular de "paternalismo" desarrollada en América Latina, donde este modelo de relaciones industriales no surgió en oposición al Estado - como había sido la tendencia en Estados Unidossino que muchas veces sirvió de complemento a los servicios públicos, manteniendo estrecha relación con las instituciones del Estado, al punto que Ángela Vergara insiste acertadamente en que el fenómeno del paternalismo industrial en América Latina coincidió con "la expansión de la legislación social, el paternalismo del Estado y, a partir de fines de mediados de la década del treinta, con los proyectos populistas" (2013: 122).

Es en este marco que surgió la institucionalización de los departamentos de Bienestar, proceso que no solo se dio en las salitreras, sino también en otros tipos de industrias modernas como la minería cuprífera y carbonífera, dentro de las cuales ésta última destaca por la concentración de estudios que recientemente ha motivado. Al respecto, compartiendo características comunes a lo se estableció en la zona salitrera, su difusión puede enmarcarse dentro de lo que, en el contexto de las lógicas paternalistas de organización industrial, Venegas ha calificado como una segunda etapa de desarrollo de los modos extensivos de control. Esta segunda etapa ha sido identificada como una "burocratización" del paternalismo, fenómeno en el cual los departamentos de Bienestar habrían venido a reemplazar al vínculo personal "cara a 
cara", establecido entre el trabajador y el patrón durante la primera etapa de organización industrial. Para el caso de la minería del carbón en Lota, este autor señala que con la burocratización "se acentuó la idea de control de la totalidad de la vida social vinculada a las empresas. Esto fue así en el sentido territorial, con el cierre de los espacios, y la intervención en todos los planos posibles dentro y fuera de la mina" (Venegas 2014: 9). Estas formas de control han sido tratadas también por otros autores para referirse al caso de Lota, el cual presenta características similares a su aplicación salitrera. Refiriéndose a una de las formas que adquirió el control extensivo, en cuanto a su dimensión espacial, Milton Godoy señala que existió una inseparable relación entre espacio y control, que llevó a la construcción del primero acorde a las necesidades productivas. Esto se habría manifestado de dos modos: por un lado, en las disposiciones espaciales de la ciudad y, por otro, en las formas de habitarla, ya que para el caso de Lota, y específicamente Lota Alto, se fue erigiendo una ciudad modelo que "era un recinto cerrado, controlado y jerarquizado que permitía vigilar los flujos de ingreso y salida del espacio urbano empresarial. Tanto las habitaciones de obreros, empleados y el sector de servicios, como el sector industrial de Lota estaban limitados por enrejados y murallas que impedían el paso de extraños y mercaderías no deseadas" (2015: 117). De ese modo, la morfología de la ciudad estuvo siempre en estrecha relación con la vigilancia interna, facilitando la supervisión de las conductas deseadas o igualmente de las indeseadas.

Esta regulación de las conductas era parte del control en las formas de habitabilidad del espacio, lo cual se relacionaba en modo directo con el control de la sociabilidad en general, como lo muestra Eduardo Godoy para el mismo caso carbonífero, donde la infraestructura de la ciudad estaba pensada para ser usada de manera tal que se "buscó imponer una especie de 'ocio racional', es decir, encauzar y dirigir desde la institucionalidad empresarial todas aquellas actividades de entretención y esparcimiento en concordancia con la regeneración social y moral propugnada por las compañías" (2015: 80). Para este fin, se habría dispuesto de una serie de "bibliotecas equipadas con una amplia gama de literatura y mobiliario, las cuales además se ocupaban en muchos casos para la realización de actividades culturales y educativas no sólo para los obreros (y operarios en general), sino también para sus proles" (Godoy 2015: 101). Esto también aplicaba al ámbito privado de los trabajadores, donde, a través de una política de premiación "para las casas más aseadas y para las que ostentaban los balcones mejor adornados", se podría recibir "el regalo de una cocina, máquina de coser u otro utensilio para el hogar" (Godoy 2015: 123).

Otra de las expresiones que tomó el control extensivo en su introducción en el escenario carbonífero fue la práctica del futbol, y Oscar Peñafiel ha señalado que, mediante la intervención directa en esta actividad a través de la creación de clubes, habría sido posible "penetrar ideológicamente entre los trabajadores y disciplinar a un altamente politizado movimiento de trabajadores" (Peñafiel 2014: 6o). Pero, más aún, esto facilitó un tipo específico de organización social al interior de los equipos, ya que, en el marco de una práctica deportiva, bajo estrictas reglas y códigos normativos, habrían podido formarse como hombres "más productivos, hegemonizados por el proyecto cultural de las elites, disciplinados para cumplir su función y guardar el comportamiento adecuado tanto dentro, como fuera del espacio de trabajo" (Peñafiel 2014: 76). La forma de organización que se trató de implantar a través de los espacios de ocio también fue llevada a la práctica en las relaciones directamente laborales. Para el mismo caso de Lota, se ha estudiado la figura del mayordomo y su desempeño en las minas, lo que les permite dar cuenta de cómo estos empleados se destacaron como atentos supervisores de las distintas fases de la producción, erigiéndose así como "un gestor experimentado de la mano de obra frente a sus subordinados. Alguien que por su ascendencia es capaz de ejercer autoridad política para distribuirlos en las faenas, determinar por dónde pueden circular y hacia qué dirección" (Venegas y Morales 2014: 86). Además, estos funcionarios realizaban un control social extensivo que abarcaba, también, aspectos cotidianos de la vida de los trabajadores, en tanto "formaron parte de los 'engranajes' formales de seguridad, una extensión a los espacios del trabajo de sus sistemas de vigilancia que mantenían en las poblaciones y centros de esparcimiento de las familias mineras, consistente en un prolífero arsenal de policías privados" (Venegas y Morales 2014: 89). De ese modo, se podía hacer más efectiva la vigilancia a través de los mismos trabajadores $y$, a su vez, establecer jerarquías entre ellos.

Unalectura algo distinta deeste proceso nos la proporciona 
el conocido activista popular Luis Ponce - quien primero fuera demócrata, luego anarquista y, finalmente, ibañista (Grez 2007: 211-220) -, al reivindicar fervientemente el papel jugado por una matriz obrera en la gestación de los departamentos de Bienestar. De acuerdo a su registro, esta iniciativa sería tributaria de la iniciativa popular y se manifestaría como una extensión concreta de la vinculación existente entre el desarrollo del movimiento popular y su politización - bajo la cuestión social—, con el robustecimiento de las demandas en torno a un cada vez más complejo programa de legislación social (Grez 2001; Artaza 2006). En concreto, para este activista, todo se debería a que, en 1905, antes de emprender un viaje a Estados Unidos, el carpintero de a bordo y dirigente anarquista de los vaporinos del puerto de Valparaíso, Ignacio Mora, habría trabajado por casi un año en la tarapaqueña oficina salitrera California, donde conoció la realidad de las condiciones de vida de los trabajadores salitreros. Reanudado su viaje, ya durante su estadía en ese país, se dedicó a trabajar en una gran fábrica manufacturera de maderas, y a su regreso a Chile, "desde Iquique se dirigió a Dolores exclusivamente a comunicar detalladamente a sus amigos pampinos las valiosas observaciones que había anotado en los Estados Unidos", entre las que "venía en forma sobresaliente la de los Departamentos de Bienestar Social". A juicio del anarquista,

“(...) en presencia de la vasta y magnifica trascendencia social que tendría para los obreros pampinos los bien entendidos Departamentos de Bienestar Social, dada la costumbre tradicional de negociación e intransigencia de los patrones salitreros para cuanto signifique un sincero progreso social obrero, nos quedamos perplejos para intentar, desde luego, su organización. No obstante esto, la idea quedó latente, viva, en espera de una ocasión favorable para hacerla surgir" (Ponce 1929: 25).

Esta oportunidad se habría presentado algunos años después, cuando acudió a Iquique la Comisión Consultiva creada por decreto gubernamental del 7 de abril de 1919, y que, compuesta por el diputado Carlos Ruiz, el presidente de la Asociación de Educación Nacional, Carlos Fernández, el director de la Oficina del Trabajo, Eugenio Frías Collao, y el director del Seminario de Ciencias Económico-Sociales de la Universidad de Chile, Daniel Martner, tenía por objetivo "estudiar las condiciones de vida y especialmente de la alimentación en dichas provincias", y proponer medidas administrativas para mejorar- las (Fernández, Ruiz, Frías y Martner 1921: 5). Ante ella, “desde la oficina 'San Antonio' de Zapiga, un grupo de obreros, en un extenso memorial, le insinuó la organización de los Departamentos de Bienestar Social, en todas las oficinas salitreras", a pesar de lo cual "la insinuación no tuvo acogida, pero la idea siempre quedó viva en el grupo de obreros que la prohijaban". De acuerdo a Ponce, ello es lo que habría explicado el impulso gubernamental a su establecimiento, ya que "cuando don Arturo Alessandri asumió la Presidencia de la República, desde la misma oficina (...) se le dirigió un memorial insinuándole la organización de los Departamentos de Bienestar Social en todas las oficinas salitreras". Sugerencia que Alessandri habría recogido favorablemente, y que estaría en la base de las acciones desplegadas por Aguirre Cerda ante la Asociación de Productores de Salitre (Ponce 1929: 25); aunque con la gran diferencia de que la orientación con que se diera en su implementación cambiaría radicalmente de registro, al pasar desde el campo de la ejecución estatal a reforzar la órbita de acción patronal.

Sea de una u otra forma, la tendencia que acabamos de describir se evidenció tempranamente en Chile en su aplicación al espacio salitrero, pues el 21 de marzo de 1921 se realizó una reunión entre el mencionado ministro y una comisión de la Asociación de Productores, en que, de acuerdo a un memorándum redactado por el gerente de la institución salitrera, "pidió el señor Ministro que los salitreros lo ayudasen en forma material y efectiva a realizar las medidas que él creyese necesarias; de otro modo, él tendría que decir en el Congreso que en el Norte los Trabajadores, vivían en forma inhumana". Insistiendo en su argumentación, Aguirre Cerda habría planteado que "los informes de las comisiones que han ido al Norte, dejan ver que los patrones no han hecho nada de lo que esas comisiones recomendaron", por lo que él solicitaba ahora "que los salitreros le den recursos y facilidades para poder llegar hasta los obreros y decirles que los salitreros han dado los dineros necesarios para satisfacer las medidas que son indispensables a su bienestar".

De acuerdo a este mismo documento, el ministro habría destacado que "de este modo, el Gobierno podría decir a los agitadores que ya no tenían razón para continuar predicando en la forma que lo hacen a los infelices a quienes engañan", concretizando su solicitud en torno a que "él desea ver que en cada oficina, se cree el Departamento 
de Bienestar a cargo de un empleado que sería algo como un intermediario entre el patrón y el obrero y que obrase con simpatía y buena voluntad, preocupándose del bienestar propiamente dicho y de las distracciones: esto es, juegos de sport, salas de espectáculo, biógrafo, reuniones sociales, etc. En esta forma el empleado del Departamento del Bienestar reemplazaría al agitador". A juicio de la autoridad política, "este empleado lo debería nombrar el Gobierno, de entre una lista que se pasaría a los salitreros y en la cual éstos elegirían a la persona", el que "sería pagado por la oficina y dependería del Administrador, quién podría suspenderlo y despedirlo". Medidas que obedecerían a que "en épocas de lucha como la actual, si ese empleado lo nombra el patrón, los obreros luego lo tomarían como espías o lo mirarían de mala voluntad. En cambio, nombrándolo el Gobierno, no habría este inconveniente", aunque siguiendo su fórmula, la subordinación - directa y explícita - respecto del administrador se mantuviera intacta. De acuerdo al ministro, estos nombramientos deberían recaer "entre el profesorado inferior y secundario, donde hay numeroso personal que reúne las condiciones esenciales que requiere el puesto" ${ }^{\prime 4}$.

A partir de la presión ministerial (Recabarren 2003: 3440), la Asociación de Productores adoptó rápidas decisiones, aunque en una dirección algo distinta a la sugerida por el gobierno. Así, en la sesión del directorio correspondiente al 30 de marzo de 1921, se designó la comisión de Bienestar Social, la que, compuesta de seis miembros, debía preocuparse "de dar forma a los propósitos indicados en los Estatutos que señalan como uno de los fines de la Asociación la atención de todo lo relacionado con el bienestar del elemento obrero", lo que a juicio de su presidente resultaba una "medida de verdadera urgencia y necesidad". En concreto, la comisión estuvo inicialmente formada por el presidente de la Asociación, Jorge $\mathrm{H}$. Jones, el vicepresidente de la misma, Walter O. Simon, junto a Moisés Astoreca, Carlos del Campo, Siegiried Gildemeister y Enrique Oyarzún, quienes asumirían la tarea de "estudiar la organización que debe darse al nuevo organismo y de buscar la persona que se haga cargo del trabajo"s.

La diferencia con la propuesta gubernamental radicaba tanto en la composición de la comisión como en su capacidad real de intervención, ya que, a juicio del ministro, pese a manifestar su agrado por la rapidez de la respuesta de la asociación y el alto nivel de sus integrantes, manifestaba reparos en el sentido de que "la circunstancia especial de no residir esas personas en la región salitrera y no serles, por consiguiente, posible ejercer una vigilancia estrecha sobre si se da o no por los interesados cumplimiento a los acuerdos de la comisión, me hace temer que su labor puede no resultar en la práctica todo lo eficaz que la situación exige, malográndose así los propósitos que sobre este particular persiguen tanto la Asociación como el Gobierno". En opinión de Aguirre Cerda, "para obviar este inconveniente, que yo considero de suma gravedad", señalaba la "conveniencia de designar personas especialmente aptas para el objeto, versadas en cuestiones sociales, de situación, sean empleados de las mismas oficinas o empleados públicos que, premunidos de las facultades necesarias, se encarguen de vigilar en todo momento porque las oficinas salitreras den estricto cumplimiento a los acuerdos adoptados por la comisión"6.

Ante esto, el gerente de la asociación se apresuró en responder que,

“(..) el propósito de mi Directorio al designar esta comisión no ha sido el de que pueda vigilar en todo momento el cumplimiento, en las oficinas salitreras, de los acuerdos adoptados. El Directorio no puede ocuparse por sí mismo del estudio de los detalles de los diversos y complejos problemas que dicen relación con el salitre. De ahí que haya delegado esa parte de su trabajo en comisiones, como la Comisión de Ventas, la Comisión Técnica y ahora la Comisión de Bienestar Social, fuera de comisiones especiales que se nombran para estudiar determinados problemas. Este procedimiento seguido en todos los cuerpos colegiados, ha dado siempre muy buenos resultados ya que para cada comisión se buscan las personas especialmente aptas para la labor a que van a dedicarse. Respondiendo a estos propósitos, la Comisión de Bienestar So cial,

4 Memorándum al Sr. Ministro el Interior, Valparaíso, 21 de marzo de 1921. En Circular Trimestral N IX, Junio de 1921, Resumen del Trimestre, p. XXVIII. Asociación de Productores de Salitre de Chile.

5 Archivo Nacional Histórico (ANH), Fondo Salitre (FS), Actas del Directorio (AD), Volumen 1229, Sesión ordinaria del Directorio del 30 de marzo de 1921. p. 20.

6 Nota del Ministro del Interior, 19 de mayo de 1921. En Circular Trimestral N IX, Junio de 1921, Resumen del Trimestre, pp. XVI y XVII. Asociación de Productores de Salitre de Chile. 
tendría como labor principal asesorar al Directorio en todo lo que diga relación con el bienestar de los obreros y estudiar y presentarle soluciones a los problemas que con tanta frecuencia se suscitan. En este orden de ideas, su labor no podría ser reemplazada por organismos extraños. Además, esta comisión central del Directorio, delegará seguramente la parte activa de inspecciones y estudio en comisiones o personas que vivan o se trasladen con frecuencia a la pampa con el fin de satisfacer los propósitos que V.S. señala y que son también los de mi Directorio. Desde luego, puedo anticiparle que las Juntas Locales en Iquique y Antofagasta que están, puede decirse, en el terreno mismo, serán los organismos ejecutivos que V.S. desea que se creen".

Para finalizar, señala su confianza en que "estas explicaciones habrán de llevar a V.S. el convencimiento de que la Comisión de Bienestar Social, tal como está constituida y en contacto permanente con el Directorio, podrá realizar una labor más práctica y positiva que una de empleados de oficinas y empleados públicos que no podrían tener injerencia ni autoridad alguna ante los productores asociados"

Resuelta así esta diferencia, la comisión comenzó a diseñar el nuevo organismo, y ya en junio de 1921, la asociación sancionaba las características que debería tener el departamento de Bienestar Social, cuya misión consistía en "promover el mejoramiento de las condiciones de vida y de trabajo de los obreros ocupados por la industria; propósitos que abarcan un sinnúmero de problemas grandes y pequeños hacia cuya solución se dirigen los esfuerzos del Departamento". El departamento estaría conducido por la comisión de Bienestar Social, entre cuyas funciones destacaba que:

"Esta Comisión lleva el control de las actividades del Departamento; interviene en las relaciones del Directorio de la Asociación con el Gobierno en los asuntos de su competencia; estudia los problemas derivados de la aplicación de las leyes sociales en la pampa; conoce de los informes y coordina la acción de los Inspectores de Bienestar Social; promueve la acción de conjunto de las Juntas Locales Salitreras en los asuntos de interés general para la industria; regula el funcionamiento de las Oficinas de Inscripción

7 Nota enviada al Ministro del Interior, 27 de mayo de 1921. En Circular Trimestral N IX, Junio de 1921, Resumen del Trimestre, p. XVII. Asociación de Productores de Salitre de Chile. de obreros; fija las normas que deben seguirse en el trabajo del Departamento y orienta la política del Directorio en materia de Bienestar Social" (Asociación de Productores de Salitre de Chile 1928: 3).

De esta comisión dependería el director del departamento de Bienestar Social, con residencia en Valparaíso, y entre cuyas funciones destacaban: "supervigila la labor de las Inspecciones de Bienestar Social; fija por intermedio del Sub-Director, rumbos a los Inspectores; organiza los trabajos estadísticos y de investigación; dirige la acción informativa y educacional del Departamento; prepara sus publicaciones; atiende la organización y funcionamiento de la Conferencia Anual de Juntas Locales Salitreras y desempeña las misiones especiales" (Asociación de Productores de Salitre de Chile 1928: 4). En la práctica, este funcionario sería el que encabezaría el organismo y serviría de enlace entre la comisión y las unidades existentes en la zona salitrera, como asimismo, de atender a sus dos secciones de operación; una primera, que "se ocupa del servicio de bienestar social propiamente dicho", está dirigida en el norte salitrero por un subdirector con residencia en el puerto de Antofagasta, y de quien dependen a su vez tres inspectores del departamento, cada uno establecido en las ciudades de Iquique, Tocopilla y Antofagasta.

En terreno, parte importante de la acción del departamento de Bienestar Social recaía en las respectivas Juntas Locales Salitreras, las que eran responsables de aplicar las disposiciones de la asociación directamente entre los productores salitreros de su respectiva localidad. De acuerdo a la asociación, la relación se definía así:

"El principal lazo de unión entre las Compañías y los Inspectores de Bienestar Social lo constituyen las Juntas Locales Salitreras, organismos complementarios de la Asociación - aunque independientes de ella- que funcionan en cada uno de los puertos de Iquique, Tocopilla, Antofagasta y Taltal. Las Juntas Locales Salitreras las forman los productores de cada región y su objeto es estudiar y resolver, de común acuerdo, todos los asuntos de interés colectivo para la región y en especial, los que se relacionan con los obreros. Los Inspectores de Bienestar Social tienen asiento en ellas en calidad de representantes de la Asociación y de colaboradores en los asuntos de su competencia" (Asociación de Productores de Salitre de Chile 1928: 4). 
En cuanto a la segunda y menos conocida sección, y aquella que no pareciera calzar fácilmente con la "misión" del departamento, era la encargada de la adecuada "provisión de operarios para la pampa", servicio que era realizado por un jefe que dependía directamente del director, y se implementaba en la práctica por las Oficinas de Inscripción de Obreros, de las cuales existían dos permanentemente establecidas - una en Santiago de Chile y otra en Valparaíso - y, ocasionalmente, de acuerdo a las necesidades de la industria, se abrirían otras en nuevos lugares del país.

En lo que respecta a la naturaleza de su función, a fines del mismo mes, por medio de una circular a todos sus asociados - la que llevó el número 52-, impulsaba la implementación de la estructura que permitiría proporcionar "debida atención a lo establecido... para llevar a efecto las ideas de mejoramiento y bienestar del obrero en que todos los industriales salitreros están empeñados". En esta circular, "en forma muy bien condensada, hace algunas recomendaciones de carácter general, las que debidamente cumplidas, contando con la cooperación de todos los asociados, dará como resultado una mayor tranquilidad y contento en la familia obrera de la pampa", existiendo claridad en que, así como había algunas que "podrían clasificarse como de inmediata ejecución, que no significan mayor desembolso de dinero y su realización traerá como resultado inmediato un mayor acercamiento entre el patrón y el obrero", existían otras que "son de ejecución no tan inmediata, pues requieren tiempo y dinero". . Tal como se reconocía que ya había asociados que se habían mostrado proclives a adoptar medidas en torno al mejoramiento de la condición de sus trabajadores desde antes incluso que la formación de la comisión, se advertía sobre las resistencias que su implementación despertaba en otros miembros, por lo que se consideró pertinente el viaje a la zona salitrera de Alberto Gómez G., quien, primero en calidad de delegado, y luego, de director del departamento de Bienestar Social cargo que desempeñó hasta 1925-, debería explicar in situ la naturaleza y alcance de las mismas, aprovechando de limar las asperezas que ellas pudieran despertar.

8 Bienestar Social. 1921. Observaciones sobre la Circular $\mathrm{N}^{\circ} 52$, Iquique, 30 de Julio de 1921. En Circular Trimestral $N^{\circ} \mathrm{X}$, Septiembre de 1921, Resumen del Trimestre. Asociación de Productores de Salitre de Chile, Valparaíso.
Pese a la amplitud de medidas y áreas de acción en torno al "bienestar del elemento obrero", la acción de Gómez se concentró en difundir las relativas a la primera de las secciones a su cargo, manteniendo reserva respecto de las segundas. De acuerdo a la misma circular, entre las grandes áreas de mejoramiento se priorizaban seis, relativas a la edificación de "nuevos y muy buenos" campamentos, para que estén "las oficinas en condiciones de ofrecer a sus obreros campamentos con habitaciones limpias, sanas y lo suficientemente espaciosas para darles comodidad a sus familias"; el cuidado de la higiene, promoviendo la instalación de servicios sanitarios; la mejora del servicio de las pulperías, en cuanto a la verificación permanente de los precios y medidas, no haciendo negocio con ellas, "sino cobrar los precios de costo", estableciendo una relación regulada con los vendedores ambulantes, de forma de poder atender mejor a los requerimientos de los obreros y controlar el ingreso de alcoholes a las oficinas; la dotación adecuada de un servicio médico, de forma de poder radicar un médico en una oficina, y que desde ahí pueda suplir las necesidades de las oficinas más cercanas, instalando pequeños hospitales, salas de curaciones ( $\mathrm{Fi}$ gura 1) y dispensarios en las oficinas, así como reorganizando los servicios de maternidad y gotas de leche en los mismos campamentos (González 2003). Efectivamente, uno de los ámbitos de acción que más rápidamente dejó ver sus positivos resultados fue una profunda transformación operada en las habitaciones de los trabajadores, lo que generó una nueva apariencia en los campamentos. De acuerdo al testimonio directo de uno de los encargados de su implementación (Figura 2), una de las primeras áreas efectivas de trabajo se vinculó al mejoramiento de las viviendas de los obreros y a la reforma de los servicios en los campamentos, destacando que "las Empresas desde hace ya algunos años se han venido preocupando del mejoramiento de la habitación y hoy los campamentos de calaminas van siendo totalmente reemplazados por construcciones de material, dándoles un simpático aspecto, a la vez que se persigue la salubridad de la población" (Torreblanca 1928: 49).

Otra de las medidas destacadas la constituía el área de los entretenimientos, que a juicio del director,

“(..) merece bastante consideración, pues mientras mayores distracciones tenga el obrero en su propia casa, que es la oficina, menos tentaciones tendrá para irlas a buscar a los pueblos 


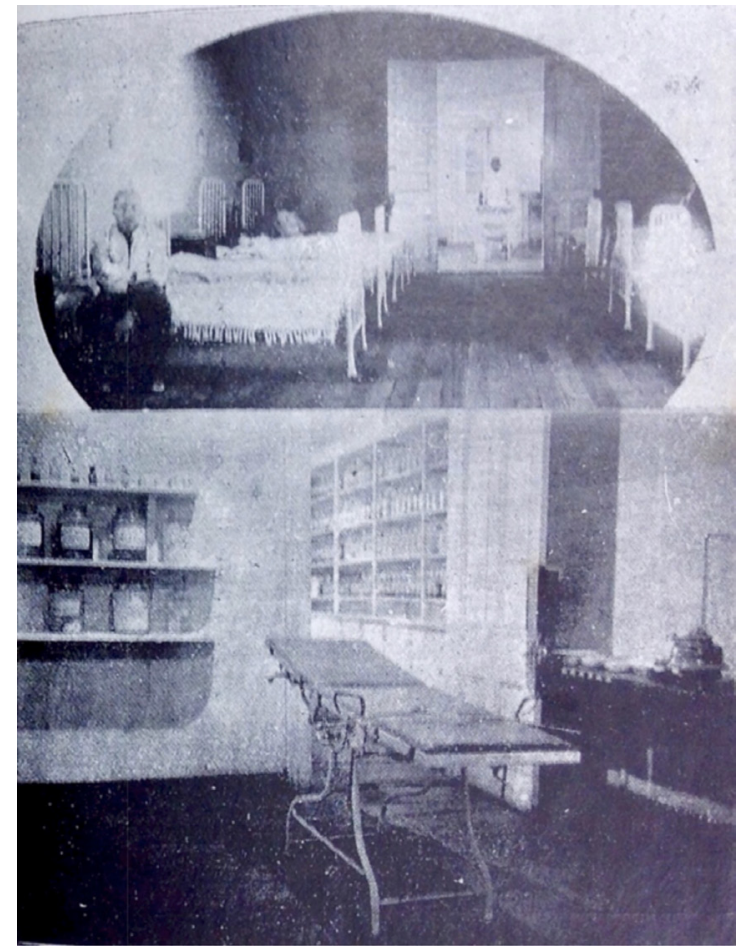

Figura 1. Pabellón de sanidad y sala de curaciones. R. Torreblanca (1928: 111).

inmediatos, en los innumerables despachos y burdeles que existen y donde el obrero además de perder su salud con el abuso del alcohol, las más de las veces falsificado; pierde también todas sus economías, dejándolas en manos del dueño del negocio, que frecuentemente es un predicador envenenado contra el trabajo y el orden y cuyo gran interés está, en convencer a su clientela que los patrones los explotan".

Así se resalta lo conveniente que resultaría ofrecer distracciones diarias "desde la hora del término del trabajo", consistente en espacios e implementos apropiados para la lectura, el canto, el baile, palitroques, deportes en general, y el uso adecuado del teatro y el biógrafo (Figura 3). Además de los entretenimientos, la instalación de buenas escuelas nocturnas y la periódica dictación de conferencias serían el instrumento adecuado para la instrucción del obrero, y contribuiría fácilmente a lograr su regeneración - como señalaba en el documento que venimos comentando-, cuyo impacto, para el caso de las escuelas, fue altamente considerable (González 2009).

Por su parte, siguiendo la misma circular, el director del departamento en las salitreras concluía destacando

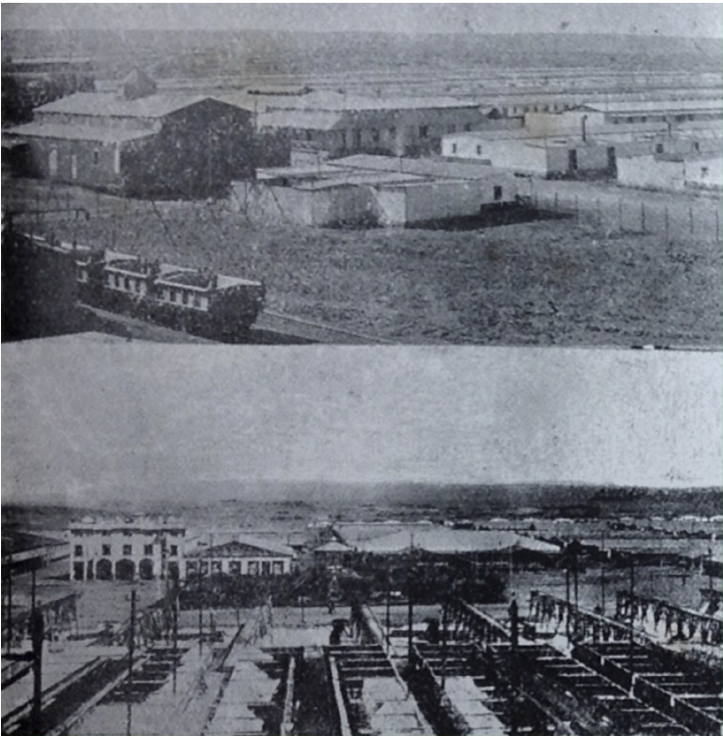

Figura 2. Fotografías de la plaza y campamento de la Oficina Chacabuco. R. Torreblanca (1928: 142).

que, para "el mejor éxito del programa de bienestar", sería fundamental "designar un empleado competente en cada oficina para que secundando al administrador, tenga a su cargo especial el de cuidar del bienestar de los obreros de las oficinas y sus familias". Aspecto que permite destaca, como ya señalamos, el carácter extensivo al que propende el control social derivado del principio del paternalismo, el que por encima del obrero mismo, buscaba implementarse sobre la familia del trabajador, ya que es gracias a ella que se ejercerá la doble función de moderar las conductas, y a la vez, permitir la reproducción futura de una mano de obra funcional y dócil a los intereses empresariales. Por lo mismo es que este empleado sería el responsable directo de ejercerlo, ya que deberá ser quien

“(...) cuidará de la moral y educación de ellos, dando conferencias de cuando en cuando o buscando alguien que las dé, atenderá sus reclamos con toda justicia y los aconsejará, fomentará el ahorro, velará por la higiene y la limpieza de los campamentos, se cerciorará que los víveres y la alimentación en general sea buena, y será el verdadero organizador de los sports y entretenimientos, en buenas cuentas, será el mantenedor del espíritu de unión tan necesario entre patrones y obreros y casi puede decirse que la vida tranquila del campamento estará entregada a su custodia". 


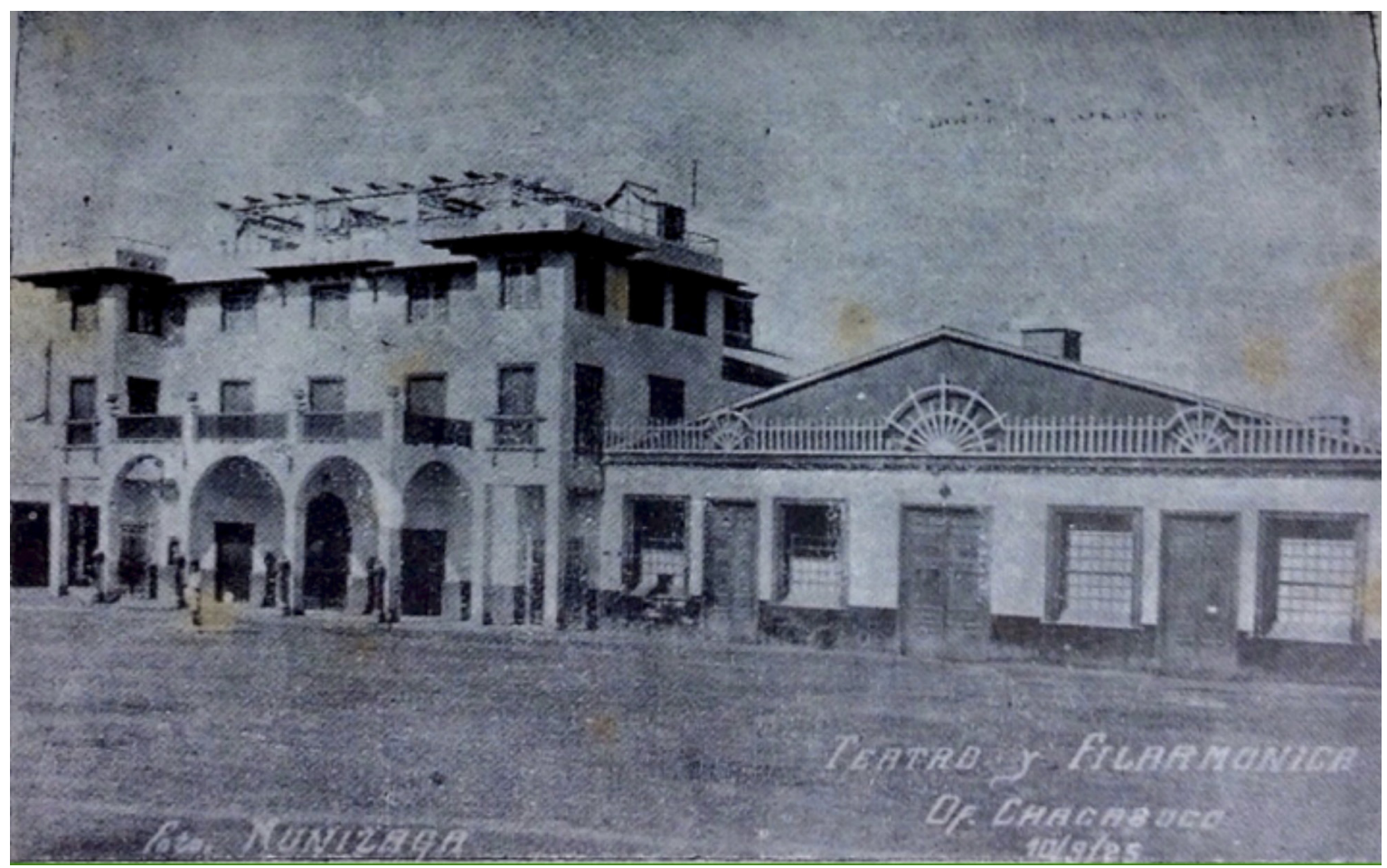

Figura 3. Teatro y filarmónica de la Oficina Chacabuco, 1925. R. Torreblanca (1928: 151).

Esta importante labor se implementaría directamente o mediante agrupamientos de dos, tres, cuatro o más oficinas, dependiendo de la cantidad de trabajadores existentes y que justificaran su implementación, tal como lo muestra el esquema del servicio de Bienestar, elaborado posteriormente por R. Torreblanca, quien llegó a desempeñarse como jefe regional de Bienestar y secretario de la dirección general de la Compañía Salitrera The Lautaro Nitrate Co (González y Sossa 2001: 104).

A partir del diagrama (Figura 4), puede apreciarse con claridad tanto la estructura de agrupamiento que debía efectuarse para la adecuada implementación de las diversas áreas que debía cubrir el servicio de bienestar en las oficinas, como asimismo de las funciones y ámbitos que debía atender el encargado de bienestar en las faenas, ya que en la franja inferior del esquema, y directamente dependiente de la dirección general de Bienestar — situándose aún por encima de la Administración de cada una de las oficinas-, se delimitan, claramente establecidas, las diversas áreas de trabajo que debían ser atendidas, cubriendo desde los aspectos derivados del cuidado por el costo de la vida, al referido a las condiciones de vida en los campamentos, la difusión de la instrucción, las cuestiones sociales, las propias del contrato de trabajo, del servicio médico e higiene y, por último, los diversos servicios públicos que se volvían disponibles en los campamentos, como correos y telégrafos o el Registro Civil. Gracias a ello, es posible apreciar la forma en que, ya con anterioridad al caso carbonífero comentado, aquí también se implementó el mismo principio de control social extensivo, donde todos los ámbitos de actividad de la mano de obra salitrera, considerando en ello tanto a los propios trabajadores como a los miembros de sus familias, tendían a quedar contemplados dentro de la esfera de acción del departamento de Bienestar social.

Sin embargo, junto a estas similitudes, respecto de lo que ocurriría con la experiencia carbonífera e igualmente con la minería cuprífera, hay un ámbito que adquiere singularidad: a pesar de la rápida instalación de la comisión, y de la efectiva puesta en marcha del departamento de Bienestar Social, e incluso de sus positivos resultados en torno a la mejoría objetiva que ello tuvo en algunas de las condiciones de vida de los trabajadores salitreros (Torreblanca 1928), parte fundamental de la actividad de la Asociación de Productores de Salitre y de la comisión de Bienestar Social estuvo orientada a la segunda sección de 


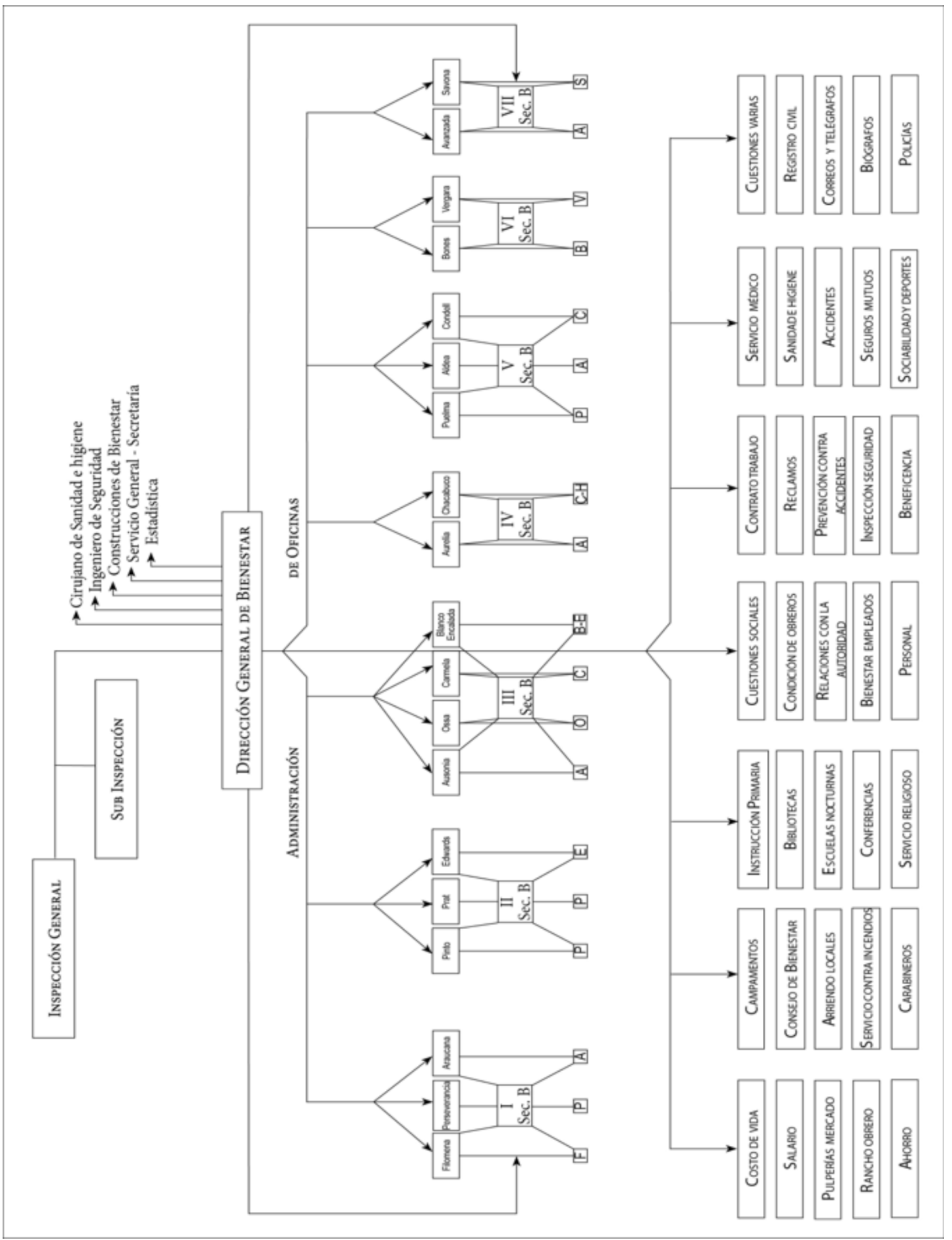

Figura 4. Diagrama del servicio de Bienestar, de acuerdo al diseñado por R. Torreblanca (1928: 31). 
operaciones; aquella destinada, mucho más directamente, hacia el control y la adecuada selección de la mano de obra. Al menos en apariencia, esto pareciera distanciarse de la "misión" que explícitamente se concentraba en torno a lograr el bienestar obrero, y que daba cuenta claramente del alcance extensivo que adquiría el control social bajo este modelo, pero que reinstalaba la centralidad de este control en aspectos mucho más directos, aunque mediante la introducción de un factor de modernización en estas funciones, que permitía superar las limitaciones de los métodos de control tradicionales, como la arbitrariedad patronal directamente ejercida por los administradores de oficinas o sus celadores, y la confección y distribución de listas negras. Dinámicas tradicionalmente aplicadas en la industria salitrera, que tenían por objetivo la exclusión de uno de los grandes males patronales, la representada por aquellos sujetos que recibían la calificación de ser "agitadores" (Pinto y Valdivia 1999; Artaza 2006; Grez 2007), pero que pese a su efectividad, tenían el inconveniente de que su aplicación solía generar solidaridad popular hacia el afectado.

Así, volviendo a nuestro relato, todo lo que restaba del año 21 se utilizó en la puesta en marcha del departamento, tanto a través de su planificación central, como de un largo viaje de su director por las provincias del norte, haciendo ver directamente a los productores la importancia de su labor y explicando las medidas prioritarias ya descritas, a la vez que detectaba las áreas en que era necesaria la participación directa del gobierno en su solución, como lo era el control del alcoholismo en la pampa y la transformación de la justicia de menor cuantía , labor para la cual los representantes del ejecutivo en la asociación jugaron un importante papel articulador.

A comienzos del año siguiente, la preocupación tanto de la asociación como de la comisión de Bienestar se centró en definir sus relaciones con la Federación Obrera de Chile (FOCh), y en la que pasaría a ser su preocupación central, la adecuada provisión de trabajadores para la industria. Así, en su sesión del 30 de marzo, el presidente de la asociación daba cuenta de la visita recibida por parte del presidente y secretario de la junta ejecutiva de la FOCh, quienes, en vista de su preocupación por la condición de los obreros, le solicitaron "ayuda para la publicación de un diario"10; solicitud que fue desestimada en tanto no estaba contemplada por los estatutos de la entidad. Junto con dar cuenta de la solicitud, el dirigente patronal estimó pertinente indicar que "los salitreros pueden hacer privadamente lo que les parezca; pero su opinión personal es que sería peligroso dar esa ayuda", lo que dio paso a un breve intercambio de opiniones entre los salitreros, quienes llegaron rápidamente al convencimiento de "no prestar ayuda", ya "que sería [un] mal precedente", dado el compromiso de esta publicación con los intereses puramente obreros ${ }^{11}$.

Ya en la reunión siguiente, la Compañía Salitrera Tocopilla hacía presente ante la asociación la compleja "situación creada a sus Oficinas por la agitación de los elementos subversivos", dando cuenta de "cómo hacen la propaganda subversiva por gente llegada del sur" y denunciando que "si no pueden tomar medidas para impedirla se verán en la necesidad imprescindible de paralizar sus Oficinas". ${ }^{12}$ A partir de lo cual - y como ya comentábamos anteriormente- se sumaba a la más tradicional y permanente de todas las labores de vigilancia del elemento obrero: aquella consistente en el control y exclusión de los "agitadores", una preocupación por la condición de los obreros que se orientó en una doble dirección, la de asegurar el cumplimiento de las disposiciones concernientes al pago de desahucios en caso de cierre de puestos de trabajo ${ }^{13}$, y de buscar implementar los mecanismos y resguardos necesario para evitar el desplazamiento de trabajadores no deseados hacia los centros de producción de salitre, reforzando con ello una de las prácticas más directas de control social. Ellas vendrían a reforzar las medidas de orden social habituales, ya que contribuirían a evitar un foco recurrente de descontento en caso de paralizaciones productivas, e intentarían asegurar la presencia del "elemento sano" entre los trabajadores.

9 ANH, FS, AD, Vol. 1229, Sesión ordinaria del Directorio del 9 de febrero de 1922, p. 264.

10 ANH, FS, AD, Vol. 1229, Sesión ordinaria del Directorio del 30 de marzo de 1922, p. 295. Esta solicitud volvió a tratarse en sesión del 18 de mayo, en donde se acordó que la asociación nada podía hacer, pero que cada compañía podría suscribir los ejemplares que deseara. P. 344.

11 ANH, FS, AD, Vol. 1229, Sesión ordinaria del Directorio del 30 de marzo de 1922, p. 296.

12 ANH, FS, AD, Vol. 1229, Sesión ordinaria del Directorio del 20 de abril de 1922, p. 304.

13 Cfr. ANH, FS, AD, Vol. 1229, Sesión ordinaria del Directorio del 27 de abril de 1922, p. 309. 
Aun así, las típicas funciones de observación y vigilancia de los obreros también se sofisticaron, aunque no siempre con buenos resultados, como se observa en el tono de decepción con que la comisión de Bienestar comunicó al directorio de la asociación "que no habían dado buenos resultados unos obreros que se habían enviado como conferencistas y trabajadores al mismo tiempo y que se buscaba otro personal que se confiaba resultaría mejor"1.14. Como bien ha destacado Aguilera, las iniciativas de bienestar social, en la minería en general, tuvieron entre uno de sus importantes objetivos el "eliminar de la clase obrera aquellos elementos más radicales", de la misma forma como más ampliamente se orientaba a prescindir de las características populares que contradecían la disciplina laboral (2015: 247-248).

Para estas nuevas funciones, rápidamente comienzan a implementarse las Oficinas de Inscripción de Obreros de Santiago y Valparaíso, las que debían registrar, visar y aprobar cada una de las contrataciones de trabajadores para las salitreras. Oficinas que, a diferencia del servicio de Colocaciones, dirigido desde la Dirección del Trabajo, no dependían del Estado sino que, por el contrario, lo hacían directamente de la entidad patronal que debía reclutarlos laboralmente. A medida que avanzaba el año 22, a partir del incremento en la necesidad de mano de obra, la capacidad de chequeo satisfactorio de esas oficinas se hizo insuficiente, por lo que a inicios de 1923 se creó una nueva Oficina de Inscripción, esta vez en la ciudad de Coquimbo, "para poder así dar oportuno cumplimiento a los numerosos pedidos de gente de las diferentes juntas locales", ya que "el pedido actualmente es de 1.900 particulares" ${ }^{\prime \prime}$, y hacia fines de octubre se anunciaba la apertura de otra Oficina en Temuco ${ }^{16}$.

Dada la importancia que cobraba esta actividad de control sobre los trabajadores que retornaban hacia las faenas salitreras, se discutió y aprobó la necesidad de contar con un ayudante del director de departamento de Bienestar, concentrado en la tarea de "satisfacer debidamente la necesidad de trabajadores de la región salitrera", labor que "requiere mucha atención y exige al mismo tiempo rapidez de acción y uniformidad de procedimientos en las distintas oficinas de inscripción"17. Gracias en parte a su labor, hasta octubre de 1923, las Oficinas de Inscripción lograron enviar, debidamente registrados y visados, 9731 obreros al norte ${ }^{18}$, los que para el mes siguiente, habían superado los 13500. Para el año siguiente, la cifra aumentó considerablemente, pues tan solo en los primeros seis meses de 1924, "se ha enviado 10.202 obreros al norte" ${ }^{\prime \prime \prime}$. El objetivo explícito de esta práctica centralizada de contratación era evitar los "enganches particulares", lo que, si bien podía aparecer como una forma de evitar los tradicionales engaños que en torno a esta actividad ocurrían, se orientaban al doble objetivo de evitar la presencia de más trabajadores que los necesarios en una zona socialmente conflictiva, y especialmente de poder filtrar y controlar el contingente de trabajadores que se reincorporaba a las labores del salitre. Ello quedó en evidencia en septiembre de 1923, oportunidad en que, frente al ofrecimiento realizado por el ministro del Interior de enviar trabajadores desocupados de Punta Arenas hacia las salitreras, el presidente de la asociación, señor Jeffery, señaló que debía actuarse con cautela, ya que "en Punta Arenas se está haciendo un buen trabajo de separación del elemento malo y posiblemente eso sea lo que desean enviar al norte"2o.

Adicionalmente, en pos de los requerimientos de la centralización en la inspección de las contrataciones, esto introducía la necesidad de revertir una antigua práctica salitrera, la que consistía en que las oficinas tendían a reclutar directamente trabajadores de otras oficinas antes que incorporar nuevos operarios, lo que llevó a que la comisión de Bienestar Social dictara un completo Reglamento de Admisión y Retiro de Operarios ${ }^{21}$, en el que la adecuada identificación de los mismos ocupaba un lugar

14 ANH, FS, AD, Vol. 1232, Sesión ordinaria del Directorio del 5 de noviembre de 1925 , p. 136.

15 ANH, FS, AD, Vol. 1229, Sesión ordinaria del Directorio del 8 de enero de 1923, p. 157; Sesión ordinaria del Directorio del 1 de junio de 1923, p. 267.

16 ANH, FS, AD, Vol. 1229, Sesión ordinaria del Directorio del 11 de octubre de 1923 , p. 356.

17 ANH, FS, AD, Vol. 1229, Sesión ordinaria del Directorio del 8 de enero de 1923, p. 158.

18 ANH, FS, AD, Vol. 1229, Sesión ordinaria del Directorio del 11 de octubre de 1923 , p. 356.

19 ANH, FS, AD, Vol. 1229, Sesión ordinaria del Directorio del 3 de julio de 1924, p. 193.

20 ANH, FS, AD, Vol. 1229, Sesión ordinaria del Directorio del 13 de septiembre de 1923 , p. 340.

21 Cfr. ANH, FS, AD, Vol. 1229, Sesión ordinaria del Directorio del 23 de marzo de 1923, p. 205. 
importante, y no exento de conflictos, tanto entre patrones como con los trabajadores ${ }^{22}$. Aun así, hacia fines del año 1923, a medida que aumentaba la necesidad de trabajadores en las salitreras, los enganches particulares se volvieron un dolor de cabeza para la asociación, ya que en muchos casos implicaba un conflicto directo entre los propios productores miembros de la sociedad, y lo que recordaba viejas prácticas de disciplinamiento de los propios patrones, como la que fue necesaria aplicar en los minerales de plata del Norte Chico casi un siglo antes, y que se tradujo en la implementación del sistema de papeletas entre los pirquineros (Illanes 1990). En el caso salitrero, las faltas patronales se enfrentaron reforzando las estructuras de control de las propias compañías productoras de salitre - por medio de la creación de un cargo de inspector para la pampa, el que debía preocuparse prioritariamente de las infracciones de enganches ${ }^{23}-\mathrm{y}$ la elaboración de un Reglamento de Enganches ${ }^{24}$, el que, en vez de estar dirigido a los obreros, recaía sobre las mismas compañías salitreras, a las que se aplicarían penas económicas en caso de infracción, como ocurrió en noviembre con la Oficina Renacimiento, a la que se le multó por $\$ 3.000$ pesos $^{25}$.

\section{* Un nuevo modelo de relaciones sociales Y LABORALES: ENTRE EL MODELO NUEVO DE LA INTERVENCIÓN SOCIAL Y EL REFORZAMIENTO DEL VIEJO CONTROL SOCIAL}

A partir de lo anterior, queda evidenciado cómo en el contexto sociopolítico de la intervención social en Chile, la trasformación de la industria salitrera constituyó una forma parcial de asumir su propia modernización en un contexto de crisis, el que lo llevó a implementar, por primera vez en el país, un modelo - el de los departamentos de Bienestar - que adquiriría luego gran presencia nacional y que, hasta cierto punto, llegó a representar la forma chilena de llevar a terreno parte importante tanto

22 Cfr. ANH, FS, AD, Vol. 1229, Sesión ordinaria del Directorio del 7 de junio de 1923, p. 273.

23 ANH, FS, AD, Vol. 1229, Sesión ordinaria del Directorio del 26 de julio de 1923, p. 306.

24 ANH, FS, AD, Vol. 1229, Sesión ordinaria del Directorio del 8 de agosto de 1923, p. 308.

25 ANH, FS, AD, Vol. 1229, Sesión ordinaria del Directorio del 8 de noviembre de 1923, p. 373. de la legislación social como de la modernización de las relaciones industriales, y que en otras áreas, como en la del cobre (Klubock 1998; Vergara 2013) y la del carbón en el Golfo de Arauco, llegaron a desplegarse con gran eficacia y perdurabilidad (Venegas, Videla y Godoy 2015). Para nuestro caso, este proceso se vio fuertemente precipitado por la profundidad que había adquirido la crisis salitrera, al punto que podría establecerse una relación directa entre la implementación de la política del bienestar como una forma de enfrentar el desafío planteado por las necesidades de modernización de las relaciones laborales en la industria del nitrato, así como también por la conflictividad social que ella había despertado.

Si bien en su diseño e implementación se guió por el peso que jugaban "las teorías en boga en ese momento en Estados Unidos, sobre la orientación profesional y la organización científica del trabajo, y que tuvieron algún grado de influencia en Chile en la forma moderna de pensar las relaciones laborales" (Yáñez 2008: 225), este cuerpo de ideas se materializó como el fruto de una negociación entre las aspiraciones reformadoras del gobierno de Alessandri y los requerimientos de transformación y reforzamiento del control de la propia industria salitrera, cuyos resultados estarían altamente presentes en la forma de traducir, en la práctica, aquellos términos eufemísticos del "bienestar", lo que fue implementado por los patrones y ampliamente utilizado por ellos en su forma de relacionarse con la fuerza de trabajo. Según Yáñez, consistían en que:

"La idea central de estas teorías estaba en organizar de manera racional el mercado del trabajo, a través de la correcta elección por parte de los trabajadores de su empleo, logrando con ello un aumento de la productividad. Se buscaba que las empresas comenzaran a contratar a sus trabajadores a partir de exámenes que indicaran claramente las habilidades de éstos para los respectivos empleos, con lo cual se garantizaría el gusto por el trabajo, el aumento de la producción y la correcta asignación de empleo a las personas que no solo lo necesitaran, sino también sirvieran para ello" (Yáñez 2008: 225).

De esto resulta que, como señala Aguilera, las políticas de bienestar social siempre estuvieron supeditadas a los beneficios económicos de las empresas (2015: 141).

AsícomonosseñalabaTorreblanca, las discusiones relativas 
a la mejor implementación de los principios de la organización científica del trabajo estuvieron muy presentes en torno a la actividad de la comisión y del departamento de Bienestar, y se expresa especialmente en torno al papel jugado por las Oficinas de Inscripción. O como el propio director del departamento informara en conferencia ante las Juntas Locales Salitreras:

"La organización científica del trabajo como estudio de las condiciones fisiológicas del trabajo, del cansancio, de la selección profesional, etc., cae precisamente dentro de los propósitos que el Departamento de Bienestar sustenta. Esto tiene, en efecto, la misión de proteger al obrero contra los sufrimientos de todas las clases que puedan afectarle y que sean susceptibles de evitarse o aminorarse. Es su misión tender a que el esfuerzo de aquel sea más suave y más útil y su tarea más agradable. La organización cientifica del trabajo persigue estos objetivos y es conveniente también para el patrón pues tiende a disminuir los costos de producción" (Asociación de Productores de Salitre de Chile 1928: 6).

Tal fue la adscripción de la comisión de Bienestar a este cuerpo de ideas que, a mediados de 1929, se sugirió y aprobó la contratación de un técnico de un instituto norteamericano especializado en la organización científica del trabajo, para que - con un costo aproximado de 15.000 dólares - pudiera hacer observaciones en terreno y luego dejar sus sugerencias de mejoramiento ${ }^{26}$.

Esta situación es la que tendería a generar una de las tensiones que se expresarían en Chile en torno a la adopción de un nuevo modelo de relaciones sociales y laborales, el que se debatiría permanentemente entre constituirse como un modelo de protección del "polo desvalido" en la relación "desigual" entre el trabajo y el capital, y el de permitir el reforzamiento de un modelo de administración industrial orientado a la racionalización de los recursos, al incremento de la productividad y a la minimización de sus costos asociados. Como hemos visto brevemente para el caso que examináramos, esta tensión no solo estuvo ampliamente presente, sino que, para la máxima entidad patronal del salitre, la preocupación de su directorio se inclinó permanentemente en torno a la priorización de estos últimos elementos.

Agradecimientos Este artículo fue desarrollado en el marco del proyecto de investigación Fondecyt $\mathrm{N}^{\circ} 1130517$, titulado "Actores subnacionales y transfronterizos y sus estrategias durante el ocaso del ciclo de expansión del nitrato: Tarapacá y Antofagasta en las décadas de los años 1920 y 1930 . Estudio desde una perspectiva regional y multiescalar", dirigido por Sergio González Miranda. Igualmente, se inscribe en el programa de investigación del Laboratoire International Associé (LIA) Mines Atacama del Centre National de la Recherche Scientifique (CNRS). Se agradece también la colaboración prestada por los ayudantes de investigación Stefan Meier y Joan Cornejo, y las gentiles observaciones de Eduardo Godoy.

26 ANH, FS, AD, Vol. 1234, Sesión ordinaria del Directorio del 16 de mayo de 1929, p. 23.

\section{$*$ Referencias Citadas}

AGUILERA, J. 2015. Minería y bienestar social en Chile, 1916-1940. En El orden fabril. Paternalismo industrial en la minería chilena 19001940, H. Venegas, E. Videla y M. Godoy. Editorial Quimantú, Santiago de Chile.

ARTAZA, P. 2006. Movimiento social y politización popular en Tarapacá, 1900 - 1912. Ediciones Escaparate, Concepción.

ASOCIACIÓN DE PRODUCTORES DE SALITRE DE CHILE. 1928. Informe del Departamento de Bienestar Social a la $3^{a}$ Conferencia de Juntas Locales Salitreras. Organización, Objeto y Programa de Acción. Sociedad Impresora y Litografía Universo, Valparaíso.
COMISIÓN CONSULTIVA DE SALITRES. 1880. Informe que la Comisión Consultiva de Salitres presenta al Señor Ministro de Hacienda. Imprenta Nacional, Santiago de Chile.

COUYOUMDJIAN, R. 1986. Chile y Gran Bretaña durante la $1^{a}$ guerra mundial y la postguerra, 1914-1921. Editorial Andrés Bello, Santiago de Chile.

DE GAUDEMAR, J. P. 1991. Nacimiento y formas de la disciplina del trabajo. Ediciones Trotta, Madrid.

FERNÁNDEZ, C., C. RUIZ, E. FRÍAS y D. MARTNER. 1921. El problema social-económico del Norte. Imprenta Central, Santiago de Chile. 
GODOY, E. 2015. Moralización, temperancia y disciplinamiento productivo en la minería del carbón (Golfo de Arauco, 19201950). En El orden fabril. Paternalismo industrial en la minería chilena 1900-1940, H. Venegas, E. Videla y M. Godoy. Editorial Quimantú, Santiago de Chile.

GODOY, M. 2015. Paternalismo industrial y construcción del espacio urbano en Lota. 1900-1950. En El orden fabril. Paternalismo industrial en la minería chilena 1900-1940, H. Venegas, E. Videla y M. Godoy. Editorial Quimantú, Santiago de Chile.

GONZÁLEZ, J. A. 2003. La pampa salitrera en Antofagasta. La vida cotidiana durante los ciclos Shanks y Guggenheim en el desierto de Atacama. Corporación Pro Antofagasta, Antofagasta.

2009. El imaginario pedagógico en las escuelas salitreras del desierto de Atacama. Revista de Historia Social y de las Mentalidades 2 (13): 91-119.

GONZÁLEZ, S. 1991. Hombres y mujeres de la pampa: Tarapacá en el ciclo del salitre. Ediciones Especiales Camanchaca $\mathrm{N}^{\circ} 2$, TER, Iquique.

2015. Normalización de la crisis y posición estratégica empresarial durante la expansión de la economía del salitre. Polis 40. En línea, disponible en: https://polis.revues.org/10799 (publicado el 17 mayo 2015).

GONZÁLEZ, S. y A. SOSSA. 2011. La vida privada de dos campamentos salitreros del cantón Bolivia durante la administración The Lautaro Nitrate $C^{\circ}$. Ltda: Ausonia y Filomena. Norte de Chile. Diálogo Andino 38: 93-110.

GREZ, S. 2001. El escarpado camino hacia la legislación social: debates, contradicciones y encrucijadas en el movimiento obrero y popular (Chile: 1901-1924). Cuadernos de Historia 21: 119-182.

2007. Los anarquistas y el movimiento obrero. La alborada de "la Idea" en Chile, 1893-1915. Lom Ediciones, Santiago de Chile.

2011. Historia del comunismo en Chile. La era de Recabarren (19121924). Lom Ediciones, Santiago de Chile.

ILLANES, M. A. 1990. Azote, salario y ley. Disciplinamiento de la mano de obra en la minería de Atacama. Proposiciones 19: 90-122.

KLUBOCK, T. 1998. Contested communities: Class, Gender, and Politics in Chile's El Teniente Copper Mine, 1904-1951. Duke University Press, Durham, N. C.

MORRIS, J. 1967. La elite, los intelectuales y el consenso. Editorial del Pacífico, Santiago de Chile.
O'BRIEN, T. 1989. "Rich beyond the Dreams if Avarice": The Guggenheims in Chile. The Business History Review 63 (1): 122-159.

OYARZUN, E., J. E. CONCHA y J. PHILIPPI. 1917. Informe presentado al Supremo Gobierno sobre las huelgas de Iquique en 1916. Informe dirigido al Ministro de Hacienda por los miembros de la Comisión. Imprenta Cervantes, Santiago de Chile.

PEÑAFIEL, O. 2014. Caballeros con la camiseta puesta. Fútbol como práctica social en Lota (1920-1950). Sud Historia 8: 57-82.

PINTO, J. 1996. Crisis salitrera y subversión social: Los trabajadores pampinos en la post-Primera Guerra Mundial (1917-1921). Boletín del Instituto de Historia Argentina y Americana Dr. Emilio Ravignani, Tercera Serie, 14: 61-92.

1997. ¿Cuestión social o cuestión política? La lenta politización de la sociedad popular tarapaqueña hacia fines de siglo (1889-1900). Historia 30: 211-261.

1999. Donde se alberga la revolución: la crisis salitrera y la propagación del socialismo obrero (1920-1923). Contribuciones Científicas y Tecnológicas 122: 115-156.

2013. Luis Emilio Recabarren. Una biografía histórica. Lom Ediciones, Santiago de Chile.

PINTO, J. y V. VALDIVIA. 1999. ¿Revolución Proletaria o querida chusma? Socialismo y Alessandrismo en la pugna por la politización pampina (1911-1932). Lom Ediciones, Santiago de Chile.

PONCE, L. 1929. La cuestión social obrera de la pampa. Artículos de Luis Ponce (Lirio Pampino). Redactor obrero de "La Provincia". Iquique.

RECABARREN, F. 2003. La matanza de San Gregorio 1921: Crisis y tragedia. Lom Ediciones, Santiago de Chile.

SANCHEZ, K. 2013. La respuesta católica a la cuestión social en Tarapacá: la doctrina social de la iglesia a través del semanario La Luz (1912-1915). Revista de Historia y Geografía 28: $13-39$.

SENNET, R. 1982. La autoridad, Alianza, Madrid.

SOTO, A. 1998. Influencia británica en el salitre. Origen, naturaleza e influencia. Editorial Universidad de Santiago, Santiago de Chile.

TORREBLANCA, R. 1928. Porlas tierras del oro blanco. Editorial Iris, Santiago de Chile.

VENEGAS, H. 2014. Paternalismo industrial y control social. Las experiencias disciplinadoras en la minería del carbón en Chile, 
Lota y Coronel en la primera mitad del siglo XX. Amérique Latine Histoire et Mémoire. Les Cahiers ALHIM 28. En línea, disponible en: http://alhim.revues.org/5099

2015. Políticas de bienestar y control social en la minería del carbón. Las experiencias de Lota y Coronel en el siglo XX. Atenea 511: $221-245$.

VENEGAS, H. y D. MORALES. 2014. Trabajo tradicional en la minería carbonífera: una aproximación a los mayordomos (19201940). Diálogo Andino 45: 85-95.

VENEGAS, H., E. VIDELA y M. GODOY. 2015. El orden fabril. Paternalismo industrial en la minería chilena 1900-1940. Editorial Quimantú, Santiago de Chile.

VERGARA, A. 2013. Paternalismo industrial, empresa extranjera y campamentos mineros en América Latina: un esfuerzo de historia laboral y transnacional. Avances del CESOR X (10): 113-128.

VIAL, G. 2001. Historia de Chile (1891-1973), Volumen III "Arturo Alessandri y los Golpes Militares (1920-1925)". Editorial ZigZag, Santiago de Chile.

VITALE, L. 1993. Interpretación marxista de la historia de Chile, Tomo IV. Lom Ediciones, Santiago de Chile.

YÁÑEZ, J. C. 1999. Antecedentes y evolución histórica de la legislación social de Chile entre 1906 y 1924. Revista de Estudios Histórico-Jurídicos 21: 203-210.

2008. La intervención social en Chile, 1907-1932. RIL editores, Santiago de Chile.

\section{Fuentes inéditas}

Archivo Nacional de la Administración (ARNAD). Fondo Oficina del Trabajo.

- Tomo 69, año 1921. Memorando enviado al Ministro de Industrias y Obras Públicas, 21 de agosto de 1921.

- Tomo 77, año 1921. Comunicación enviada al Director de la Oficina Internacional del Trabajo en Ginebra, 14 de noviembre de 1921.

Archivo Nacional Histórico (ANH), Fondo Salitre (FS), Actas del Directorio (AD).
Volumen 1229:

- Sesión ordinaria del Directorio del 30 de marzo de 1921.

- Sesión ordinaria del Directorio del 9 de febrero de 1922.

- Sesión ordinaria del Directorio del 30 de marzo de 1922.

- Sesión ordinaria del Directorio del 18 de Mayo de 1922.

- Sesión ordinaria del Directorio del 20 de abril de 1922.

- Sesión ordinaria del Directorio del 27 de abril de 1922.

- Sesión ordinaria del Directorio del 8 de enero de 1923.

- Sesión ordinaria del Directorio del 23 de marzo de 1923

- Sesión ordinaria del Directorio del 1 de junio de 1923.

- Sesión ordinaria del Directorio del 7 de junio de 1923.

- Sesión ordinaria del Directorio del 26 de julio de 1923.

- Sesión ordinaria del Directorio del 8 de agosto de 1923.

- Sesión ordinaria del Directorio del 13 de septiembre de 1923.

- Sesión ordinaria del Directorio del 11 de octubre de 1923.

- Sesión ordinaria del Directorio del 8 de noviembre de 1923.

- Sesión ordinaria del Directorio del 3 de julio de 1924.

Volumen 1232:

- Sesión ordinaria del Directorio del 5 de noviembre de 1925.

Volumen 1234:

- Sesión ordinaria del Directorio del 16 de mayo de 1929.

\section{Publicaciones periódicas}

Asociación de Productores de Salitre de Chile.

Circular Trimestral $N^{\circ}$ IX, Junio de 1921, Resumen del Trimestre. R. Magowan, Imprenta y Litografía Inglesa, Valparaíso, 1921.

- Memorándum al Sr. Ministro el Interior, Valparaíso, 21 de marzo de 1921.

- Nota del Ministro del Interior, 19 de mayo de 1921.

- Nota enviada al Ministro del Interior, 27 de mayo de 1921.

Circular Trimestral $N^{\circ} X$, Septiembre de 1921, Resumen del Trimestre, R. Magowan, Imprenta y Litografía Inglesa, Valparaíso, 1921.

Bienestar social. Observaciones sobre la Circular $\mathrm{N}^{\circ} 52$, Iquique, 30 de Julio de 1921.

Revista Zig-Zag, 12 de febrero de 1921.

La Provincia, Iquique, 11 de enero de 1919.

El Despertar de los Trabajadores, Iquique, 7 de enero de 1921.

El Despertar de los Trabajadores, Iquique, 9 de enero de 1921. 